\title{
Analisis Beban Kerja Untuk Mengetahui Jumlah Pekerja Optimal Karyawan Polishing 3 Dengan Menggunakan Metode Workload Analysis Di Pt Surya Toto Indonesia,Tbk
}

\author{
${ }^{1}$ Tri Widodo, ${ }^{2}$ Ismail Fardiansyah, ${ }^{3}$ Trisna Wiharta \\ ${ }^{1,2}$ Staff Pengajar Program Studi Teknik Industri, Fakultas Teknik \\ ${ }^{3}$ Mahasiswa Teknik Industri, Fakultas Teknik \\ Jurusan Teknik Industri, Fakultas Teknik Universitas Muhammadiyah Tangerang \\ Jl. Perintis Kemerdekaan I/33, Cikokol, Kota Tangerang. \\ Email: tiga_wd@yahoo.co.id; fardiansyahismail@yahoo.com; trisnawiharta93@gmail.com
}

\begin{abstract}
ABSTRAK
Sumber daya manusia merupakan salah satu komponen yang sangat penting dalam perusahaan. Pada proses produksi di bagian polishing $3 \mathrm{PT}$. Surya Toto Indonesia masih menggunakan tenaga manusia dan jumlah tenaga kerja yang belum efektif. Sehingga perlu dilakukan tindakan penelitian untuk menentukan jumlah pekerja yang optimal. PT Surya Toto Indonesia merupakan salah satu perusahaan yang bergerak di bidang manufaktur yang menghasilkan produk fitting, sanitary, dan kitchen set. Tujuan dari penelitian ini diantaranya untuk mengetahui presentasi produktif pekerja dalam suatu kegiatan observasi secara langsung, untuk mengetahui waktu baku sesuai dengan waktu observasi yang diperoleh, dan untuk mengetahui jumlah karyawan yang optimal pada Polishing 3 . Dalam penelitian ini akan dilakukan perhitungan jumlah pekerja optimal dengan menggunakan metode Workload Analysis dimana pengukuran kerja dilakukan terlebih dahulu kepada 10 pekerja menggunakan Work Sampling sehingga akan diperoleh nilai waktu baku. Hasil dari penelitian ini menunjukkan bahwa hasil presentasi produktif sebesar $71 \%$. Sedangkan waktu baku yang diperoleh dalam penelitian ini sebesar 13,53 menit. Jumlah karyawan optimal yaitu sebesar 8,85 orang yang dalam hal ini dapat diekuivalenkan menjadi 9 orang. Sehingga hasil analisis beban kerja menunjukkan bahwa jumlah pekerja karyawan Polishing 3 masih belum optimal.
\end{abstract}

Kata Kunci: Work Sampling,Workload Analysis, Jumlah Pekerja Optimal

\section{PENDAHULUAN}

Dalam penelitian ini difokuskan pada peningkatkan efisiensi pada bidang Sumber Daya Manusia. Efisiensi dalam bidang SDM berkaitan dengan aktivitas kerja dan waktu yang dibutuhkan karyawan untuk menyelesaikan tugas - tugasnya sesuai dengan Job Description yang diberikan oleh pihak manajemen. Metode yang digunakan dalam penelitian ini yaitu Work Load Analysis yang merupakan gambaran dari beban kerja yang dibutuhkan dalam suatu organisasi pada suatu perusahaan. Dengan metode ini dapat memberikan informasi mengenai pengalokasian sumber daya karyawan dalam menyelesaikan beban kerjanya.

Permasalahan yang dihadapi perusahaan adalah peningkatan efesiensi yaitu penentuan jumlah pekerja yang optimal berdasarkan produktivitas pada Departemen Polishing 3 dengan metode Work Load Analysis. Untuk lebih mengetahui sejauh mana pengaruh jumlah pekerja optimal dengan cara melakukan observasi kepada karyawan polishing 3 di PT. Surya Toto Indonesia,tbk maka dibutuhkan suatu penelitian yang komperhensif dengan judul " Analisis Beban Kerja Untuk Mengetahui Jumlah Pekerja Optimal Karyawan Polishing 3 Dengan Menggunakan Metode Work Load Analysis Di PT. Surya Toto Indonesia,tbk.

Rumusan masalah dalam penelitian ini diantaranya Bagaimana cara menentukan tingkat presentase produktivitas pada bagian polishing 3, Bagaimana cara menentukan waktu baku untuk part S 40228-1, dan Berapakah jumlah pekerja optimal karyawan polishing 3 . 
Tujuan dari penelitian ini yaitu mengetahui presentase produktivitas karyawan Polishing 3 sesuai dengan waktu observasi, mengetahui waktu baku Part S 40228-1 sesuai dengan waktu observasi, mengetahui jumlah karyawan yang optimal pada polishing 3 .

\section{TINJAUAN PUSTAKA}

\section{Sumber Daya Manusia}

Sumber daya manusia adalah salah satu faktor yang sangat penting bahkan tidak dapat dilepaskan dari sebuah organisasi, baik institusi maupun perusahaan. Sumber daya manusia juga merupakan kunci untuk menentukan perkembangan perusahaan. Pada hakikatnya, SDM berupa manusia dipekerjakan disebuah organisasi sebagai penggerak, pemikir dan perencana untuk mencapai tujuan organisasi itu. Menurut Anggraeni dan Prabowo (2015) Manajemen sumber daya manusia adalah suatu ilmu atau cara bagaimana mengatur hubungan dan peranan sumber daya (tenaga kerja) yang dimiliki secara efisien dan efektif serta dapat digunakan secara maksimal sehingga tercapai tujuan (goal) bersama perusahaan, karyawan dan masyarakat menjadi maksimal.

\section{Metode Workload Analysis}

Metode Work Load Analysis dapat diartikan sebagai suatu proses untuk menghitung beban kerja pada suatu posisi / sub-posisi dan juga kebutuhan jumlah orang untuk mengisi posisi / sub posisi tersebut. Dalam metode ini terdapat tiga hal utama yang akan harus ditentukan yaitu:

1. Menentukan output / keluaran utama dari suatu fungsi / sub-fungsi dan kemudian mengidentifikasi rangkaian aktivitas kerja yang dibutuhkan untuk menghasilkan output tersebut.

2. Menentukan waktu yang tersedia tiap pekerja atau operator.

3. Menentukan waktu baku yang dibutuhkan untuk menyelesaikan per kelompok tugas tersebut.

\section{METODE PENELITIAN}

Penelitian ini dilakukan di PT Surya Toto Indonasia, Tbk selama 1 bulan terhitung dari tanggal 01 Juli sampai 31 Juli 2017. Penelitian dilakukan pada hari kerja dan jam kerja, hari kerja senin-jumat pukul 08.000-17.00 WIB. Data yang diambil pada penelitian ini adalah data dari bagian polishing 3 dimana sampel yang digunakan dalam penelitian ini berjumlah 10 orang. Teknik Pengumpulan data dalam penelitian ini diperoleh dari data primer (melakukan pengukuran terhadap kinerja karyawan yaitu data jam kerja aktual karyawan) dan data sekunder (diperoleh dari studi literature, baik dari tulisan, referensi yang relevan, jurnal - jurnal yang berkaitan, data dari perusahaan maupun sumber-sumber lain yang menunjang penelitian). 


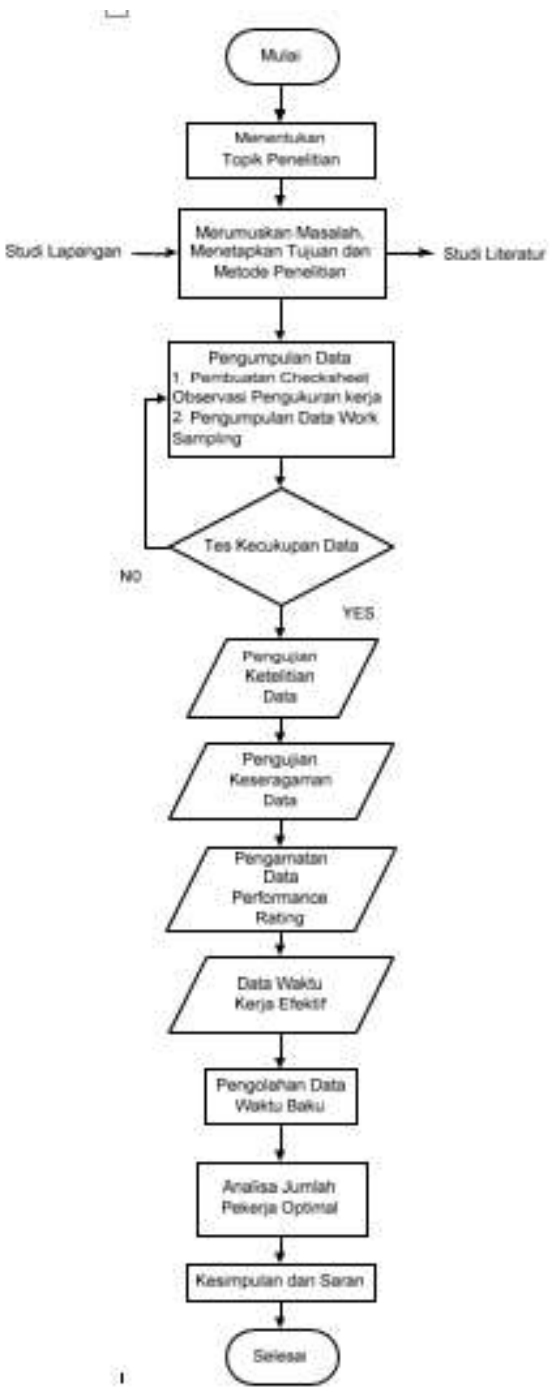

Gambar 1. Metodologi Penelitian

\section{HASIL DAN PEMBAHASAN}

\section{Pengumpulan Data}

Tabel 1. Hasil Pre-Study Sampel Kerja Operator Polishing 3

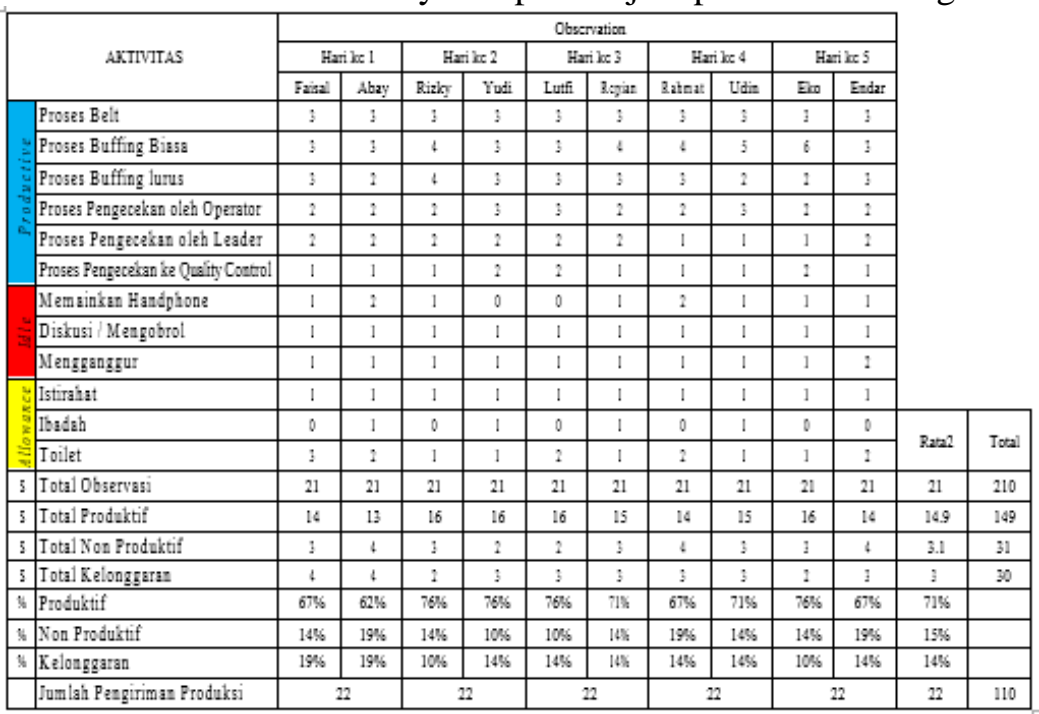

\section{Pengujian Kecukupan Data}




$$
\begin{aligned}
& \mathrm{N}^{\prime}=\frac{\mathrm{K}^{2}(1-\mathrm{P})}{\mathrm{S}^{2} \mathrm{P}} \\
& \mathrm{N}^{\prime}=\frac{2^{2}(1-0,709)}{0,1^{2} \mathrm{~S} 0,709} \\
& \mathrm{~N}^{\prime}=\frac{4^{2}(0,291)}{0,01 \mathrm{~s} 0,709} \\
& \mathrm{~N}=\frac{1164}{0,00709} \\
& \mathrm{~N}=164 \text { Minimum data pengamatan }
\end{aligned}
$$

Dari hasil perhitungan diatas dapat diamati bahwa N: $210>$ N: 164 sehingga dapat diasumsikan bahwa data pengamatan sampel kerja dianggap sudah cukup.

\section{Pengujian Tingkat Ketelitian Data Pengamatan}

$$
\begin{aligned}
\mathrm{S} & =\mathrm{k} \frac{f \overline{\mathrm{P}(1-\mathrm{P})}}{\mathrm{N}} \\
& =2 \frac{f \overline{0.709(1-0.709)}}{210} \\
& =2 \frac{\sqrt{0.2063}}{210} \\
& =25 \overline{0.00098} \\
& =2(0.031) \\
& =0.062 \text { atau } 6,2 \%
\end{aligned}
$$

Karena dalam penelitian ini harga $\mathrm{S}=6,2 \%$ adalah lebih kecil dari $10 \%$ (derajat ketelitian yang ditetapkan pada batasan masalah) maka jumlah pengamatan acak yang sudah dilakukan sebanyak 210 kali akan cukup memenuhi syarat ketelitian yang ditetapkan.

\section{Pengujian Keseragaman Data}

Rata-rata presentase kegiatan produktif $\mathrm{P}=0,709$

BKA dan BKB

$$
\begin{aligned}
\text { BKA } & =P+3 \frac{\overline{J^{P(1-P)}}}{\mathrm{N}} \\
& =0.709+3 \frac{\mathrm{J} \frac{\overline{0,709(1-0,709}}{210}}{} \\
& =0,709+3 \frac{\overline{0,206}}{210} \\
& =0,709+3 \sqrt{0,00098} \\
& =0,709+3(0,031) \\
& =0,709+0,093
\end{aligned}
$$$$
B K B=P-3 J \frac{\overline{P(1-P)}}{N}
$$$$
=0.709-3 \mathrm{~J} \frac{\overline{0,709(1-0,709)}}{210}
$$

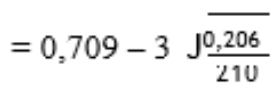$$
=0,709-3 \sqrt{0,00098}
$$$$
=0,802
$$ 


$$
\begin{aligned}
& =0,709-3(0,031) \\
& =0,709-0,093 \\
& =0,616
\end{aligned}
$$

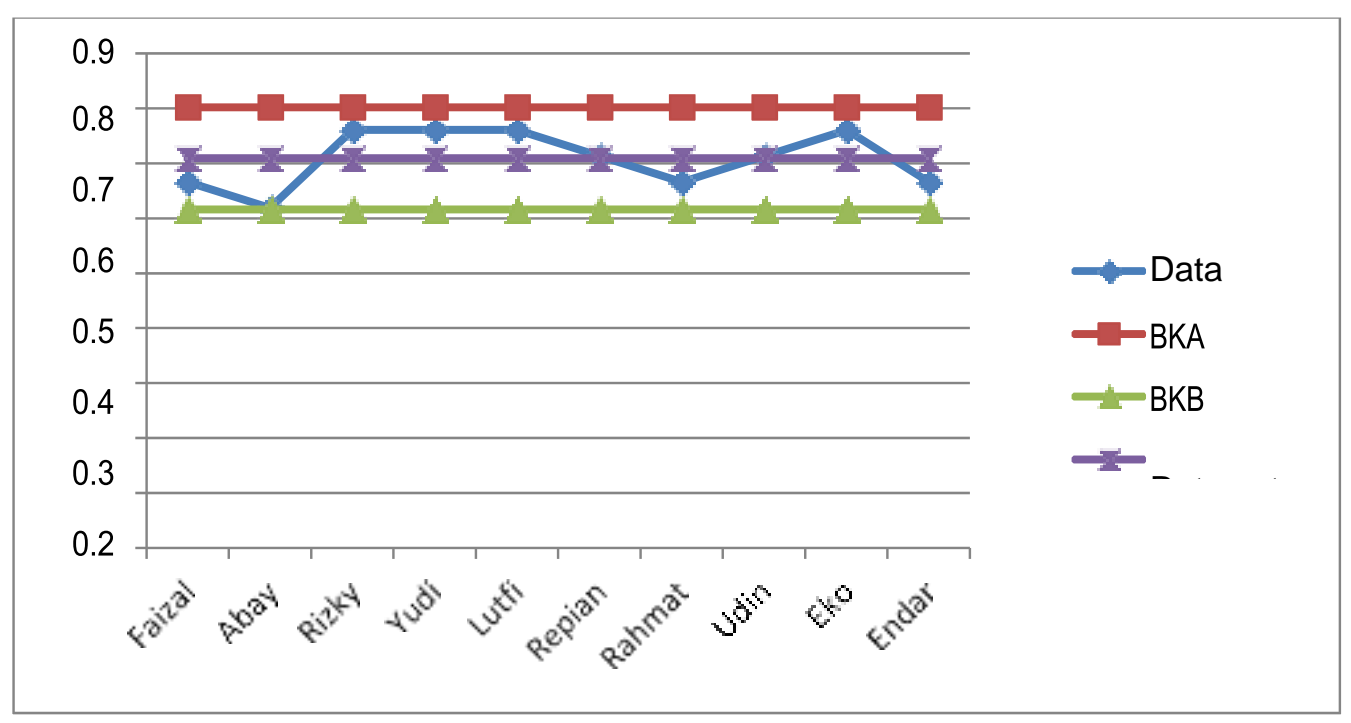

Gambar 2. Grafik Peta Kontrol Data Persentase Waktu Produktif

\begin{tabular}{|c|c|c|c|c|c|c|c|c|c|c|c|c|c|}
\hline \multirow{4}{*}{\multicolumn{2}{|c|}{ Klaxitionay }} & \multirow{4}{*}{\multicolumn{2}{|c|}{ Hating }} & \multicolumn{10}{|c|}{ Numu Cperater } \\
\hline & & & & \multirow{3}{*}{\multicolumn{2}{|c|}{ 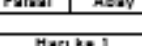 }} & \multirow[t]{2}{*}{ IRriky } & \multirow[t]{2}{*}{$\begin{array}{l}\text { Yudi } \\
\end{array}$} & \multicolumn{2}{|c|}{ 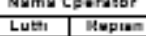 } & \multirow[t]{2}{*}{ |exhimat| } & \multirow[t]{2}{*}{ Udin } & \multirow[t]{2}{*}{ EkD } & \multirow[t]{2}{*}{ Endar } \\
\hline & & & & & & & & \multicolumn{2}{|c|}{ 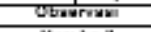 } & & & & \\
\hline & & & & & & & & & $k=3$ & \multicolumn{2}{|c|}{ Marike 4} & \multicolumn{2}{|c|}{ Marikes } \\
\hline \multirow{11}{*}{ 衷 } & \multirow{2}{*}{ Supersikil } & $A 1$ & 0.15 & & & & & & & & & & \\
\hline & & $A 2$ & 0.12 & & & & & & & & & & \\
\hline & \multirow{2}{*}{ Excevent } & $E 1$ & 0.1 & 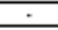 & & & & & & & & - & 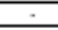 \\
\hline & & $\mathrm{BZ}$ & 0.05 & & $\cdot$ & & $\cdot$ & & & $\cdot$ & - & & \\
\hline & \multirow{2}{*}{ Good } & C1 & 0.04 & & & & & $\cdot$ & $\cdot$ & & & & \\
\hline & & $\mathrm{Cz}$ & 0.0 .5 & & & & & & & & & & \\
\hline & Averege & 0 & & & & & & & & & & & \\
\hline & \multirow{2}{*}{ rom } & $E 1$ & -2.05 & & & & & & & & & & \\
\hline & & $E 2$ & -9. & & & & & & & & & & \\
\hline & \multirow{2}{*}{ Door } & $r 1$ & -0.15 & & & & & & & & & & \\
\hline & & $r 2$ & -4.25 & & & & & & & & & & \\
\hline \multirow{11}{*}{ รู } & \multirow{2}{*}{ Eresinive } & $A 1$ & 0.15 & & & & & & & & & & \\
\hline & & $A 2$ & 0.12 & & & & & & & & & & \\
\hline & & E1 & a.s. & & & & & & & & & & \\
\hline & Excellent & $\mathrm{Ez}$ & 0.05 & & $\cdot$ & & & & & & & & \\
\hline & & C1 & $0.0 \mathrm{~s}$ & & & & & & . & & - & & \\
\hline & Good & $\mathrm{cz}$ & 0.0 .4 & $\cdot$ & & & & $\cdot$ & & $\cdot$ & & - & - \\
\hline & Averege & 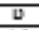 & & & & $\cdot$ & $\cdot$ & & & & & & \\
\hline & & $E 1$ & -1.04 & & & & & & & & & & \\
\hline & Fair & $E_{2}$ & -0.08 & & & & & & & & & & \\
\hline & & $r 1$ & $-\sqrt{-1.12}$ & & & & & & & & & & \\
\hline & Door & $r z$ & -9.17 & & & & & & & & & & \\
\hline tे & lateal & A & 0.04 & & & & & & & $\cdot$ & & & \\
\hline 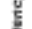 & Exceñent & 8 & 0.05 & & & & & & $\cdot$ & & & & \\
\hline 8 & Good & $\tau$ & 0.0 & & $\cdot$ & & $\cdot$ & & & & - & & - \\
\hline है & Averege & D & & . & & $\cdot$ & & & & & & 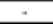 & \\
\hline 8 & rair & $E$ & -0.0 .2 & & & & & & & & & & \\
\hline & Foor & $\mathrm{F}$ & -0.04 & & & & & & & & & & \\
\hline & laten & A & 0.06 & & & & & & & & & & \\
\hline g & Exceñ̄ent & 8 & 0.04 & $\cdot$ & & - & & & & & & & \\
\hline 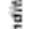 & Good & c & 0.0 .2 & & $\cdot$ & & & 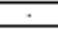 & & & & - & \\
\hline ह5 & Averege & D & & & & & $\cdot$ & & $\cdot$ & & 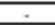 & & - \\
\hline & rair & $E$ & -9.07 & & & & & & & - & & & \\
\hline & Poor & $\mathrm{P}$ & -0.07 & & & & & & & & & & \\
\hline & & & Iatal & 0.17 & 0.12 & 0.15 & 0.05 & 0.1 & 0.13 & 0.14 & 0.14 & 0.15 & 0.14 \\
\hline & $\mid=-(1-0.14\}$ & & Rata2 & & & & & & 14 & & & & \\
\hline
\end{tabular}

\section{Data Pengamatan Performance Rating}

Tabel 2. Hasil Evaluasi Penilaian Performance Rating 


\section{Data Waktu Kerja Efektif}

Tabel 3. Jumlah Hari Kerja Efektif selama tahun 2016

\begin{tabular}{|l|c|}
\hline \multicolumn{1}{|c|}{ Keterangan } & Jumlah hari \\
\hline Jumlah hari dalam setahun & 365 hari \\
\hline Jumlah hari cuti bersama & 6 hari \\
\hline Jumlah hari cuti individu & 6 hari \\
\hline Jumlah libur nasional & 14 hari \\
\hline Jumlah hari sabtu dan minggu & 105 hari \\
\hline Jumlah hari kerja Efektif & 234 hari \\
\hline
\end{tabular}

Berdasarkan perhitungan jumlah hari kerja efektif pada tabel 4.5 maka dapat dihitung pula jumlah jam kerja efektif selama setahun yaitu dengan mengalikan jumlah hari kerja efektif dengan jam kerja per hari sehingga didapatkan jumlah jam kerja efektif tahun 2016 sebesar 234 x 9 jam $=2.106 \mathrm{Jam}$.

$\ln \times r \times r$

$$
\begin{aligned}
\mathrm{Wn} & =\frac{\mathrm{Np}}{} \\
& =\frac{2.100 \times 0,709 \times 0,86}{110} \\
& =\frac{1.280,454}{110} \\
& =11,64
\end{aligned}
$$$$
\mathrm{Wb}=\mathrm{Wn} \times \frac{100 \%}{100 \% \text {-aSSowance }}
$$$$
\begin{aligned}
& =11,64 \times \frac{1}{1-0.14} \\
& =11,64 \times \frac{1}{0.86}
\end{aligned}
$$$$
=11,64 \times 1,1628
$$$$
=13,53
$$

Dari hasil perhitungan di atas dapat diketahui bahwa waktu baku yang diperlukan oleh operator polishing untuk melakukan suatu proses pengiriman barang sampai dengan semua persyaratan diselesaikan adalah selama 13,53 menit.

\section{Analisis Jumlah Pekerja Optimal}

$$
\mathrm{N}=\frac{\mathrm{P} s M b}{\mathrm{D} s \mathrm{E}(79 \%)}
$$

$$
\begin{aligned}
& =\frac{65 \cdot 232 \mathrm{~s} 13,53}{126 \cdot 360 \mathrm{~s} 0,79} \\
& =\frac{882 \cdot 588,96}{99 \cdot 824,4}=8,84 \text { atau menjadi } 9 \text { orang }
\end{aligned}
$$

Berdasarkan perhitungan diatas dapat dilihat bahwa didapatkan jumlah pekerja optimal yaitu sebesar 8,84 orang yang dalam hal ini dapat di ekuivalenkan menjadi 9 orang.

\section{KESIMPULAN DAN SARAN}

\section{Kesimpulan}

Adapun kesimpulan yang dapat diambil dari penelitian mengenai pengoptimalan jumlah tenaga kerja pada karyawan Polishing 3 sebagai berikut : 
1. Jumlah persentase produktivitas karyawan Polishing 3 selama waktu observasi adalah sebesar $71 \%$.

2. Jumlah waktu baku yang dibutuhkan untuk Part S 40228-1 selama waktu observasi adalah sebesar 13,53 menit.

3. Jumlah pekerja optimal karyawan polishing 3 selama waktu observasi adalah sebanyak 9 orang dari 10 orang yang dilakukan observasi dirasa cukup untuk mengatasi beban kerja yang ditetapkan perusahaan untuk bagian Polishing 3 .

\section{Saran}

1. Pada penelitian ini tentu saja tidak lepas dari berbagai kekurangan dan keterbatasan baik dari segi peneliti maupun kondisi waktu yang terbatas dalam melakukan penelitian. Salah satu kekurangan dalam penelitian ini diantaranya yaitu jumlah pengambilan data sampel kerja yang dianggap terlalu minim karena dilakukan hanya 5 hari saja, walaupun secara perhitungan data tersebut dianggap mencukupi untuk menganalisa tentang jumlah karyawan yang optimal pada bagian polishing 3 PT. Surya Toto Indonesia,tbk.

2. Apabila suatu saat akan dilakukan penelitian kembali tentang kasus ini maka disarankan untuk peneliti mempunyai waktu penelitian yang tidak terbatas agar didapatkan data yang lebih bervariasi, karena sangat berpengaruh pada nilai waktu baku yang dihasilkan.

\section{DAFTAR PUSTAKA}

Ajitia, Muhammad Ghantar., \& Prasetya, Arik. (2017). Efektivitas Manpower Planning Dengan Menggunakan Metode Analisis Beban Kerja (Work Load Analysis) Berdasarkan Pendekatan Full Time Equivalent (Studi Pada Divisi Pengembangan Karir, Organisasi, dan Kompetensi di PT. Pupuk Kalimantan Timur, Tbk Bontang, Kalimantan Timur). Jurnal Administrasi (JAB)|Vol. 42 No. 1 Januari 2017. Malang: Fakultas Ilmu Administrasi, Universitas Brawijaya.

Anggraeni, Linanda Eka., \& Prabowo, Rony. (2015). Analisis Beban Kerja untuk Menentukan Jumlah Karyawan Optimal (Studi Kasus: PT. Sanjayatama Lestari Surabaya). Seminar Nasional Sains dan Teknologi Terapan III 2015. Surabaya: Jurusan Teknik Industri, Fakultas Teknologi Industri, Institut Teknologi Adhi Tama.

Arif, Riduwan. (2014). Analisa Beban Kerja dan Jumlah Tenaga Kerja yang Optimal Pada Bagian Produksi dengan Pendekatan Metode Work Load Analysis (WLA) di PT. Surabaya Perdana Rotopack. Jawa Timur: Jurusan Teknik Industri, Universitas Pembangunan Nasional.

Koesomowidjojo, Suci R. Mari'ih. (2017). Panduan Praktis Menyusun Analisis Beban Kerja. Jakarta: Raih Asa Sukses.

Lituhayu, Rizaini. (2008). Analisis Beban Kerja dan Kinerja Karyawan (Studi Kasus pada Head Office PT. Lerindro Internasional Jakarta (Skripsi). Departemen Manajemen, Fakultas Ekonomi dan Bisnis, Institut Pertanian Bogor, Bogor.

Realdo, Yudinta Vino. (2015). Analisa Beban Kerja dalam Penentuan Jumlah Pekerja Optimal dan Pengaruhnya terhadap Kinerja Karyawan Studi Kasus di PT Asia Trade Perkasa Jalan Lingkar Bantul, Ngimbang, Pendowoharjo, Sewon, Bantul, Yogyakarta (Skirpsi). Program Studi Teknik Industri, Fakultas Sains dan Tekonologi, Universitas Islam Negeri Sunan Kalijaga, Yogyakarta.

Sedarmayanti. (2009). Sumber Daya Manusia dan Produktifitas Kerja. Bandung: CV Mandar Maju. 
Singgih, Moses L., \& Anggraeni, Yanti. (2007). Work Load Analysis dan Job Analysis Untuk Penentuan Jumlah Karyawan yang Optimal dan Pengalokasian Karyawan pada Pekerjaan yang Sesuai dengan Karakteristik dan Kemampuannya (Studi Kasus di Cv.Player.com). Prosiding Seminar Nasional Manajemen Teknologi

VI. Surabaya: Jurusan Teknik Industri, Institut Teknologi Sepuluh November.

Singgih, Moses L., \& Dewita, Ellyn. (2008). Analisis Beban Kerja Karyawan pada Departemen Umum dan Logistik dengan Metode Work Load Analysis di Perusahaan Percetakan. Prosiding Seminar Nasional Teknoin. Surabaya: Jurusan Teknik Industri, Institut Teknologi Sepuluh November.

Soemohadiwidjojo, Arini T. (2017). KPI (Key Performance Indicator) untuk Perusahaan Jasa

Triswandana, Michael Sidhi. (2011). Penentuan Jumlah Optimal Operator Pemindahan Unit Mobil pada Vehicle Logistic Center Perusahaan Manufaktur Otomotif dengan Pendekatan Workload Analysis (Skripsi). Fakultas Teknik, Program Teknik Industri , Universitas Indonesia, Depok.

Wibowo. (2016). Manajemen Kinerja Edisi Kelima. Jakarta: Rajawali Pers. 